\title{
Power load limits of the WENDELSTEIN 7-X target elements - comparison of experimental results and design values for power loads up to the critical heat flux-
}

\author{
H. Greuner ${ }^{\mathrm{a}, *}$, B. Boeswirth ${ }^{\mathrm{a}}$, J. Boscary ${ }^{\mathrm{a}}$, A Leuprecht $^{\mathrm{b}}$, A. Plankensteiner ${ }^{\mathrm{b}}$ \\ ${ }^{\mathrm{a}}$ Max-Planck-Institut für Plasmaphysik, Euratom Association, Boltzmannstr. 2, D-85748 Garching, Germany \\ ${ }^{\mathrm{b}}$ PLANSEE SE, A-6600 Reutte, Austria
}

\begin{abstract}
The power load limits of the WENDELSTEIN7-X divertor target elements were experimentally evaluated with heat loads considerably exceeding the expected operating conditions. The water-cooled elements are designed for steady-state heat flux of 10 $\mathrm{MW} / \mathrm{m}^{2}$ and to remove a power load up to $100 \mathrm{~kW}$. The elements must allow a limited operation time at $12 \mathrm{MW} / \mathrm{m}^{2}$ steady-state and should not fail for short pulses of up to $15 \mathrm{MW} / \mathrm{m}^{2}$ for cooling conditions in the subcooled nucleate boiling regime. In the framework of the qualification phase, pre-series target elements were loaded up to $24 \mathrm{MW} / \mathrm{m}^{2}$ without loss of CFC tiles.

A critical heat flux at the target of $31 \mathrm{MW} / \mathrm{m}^{2}$ was achieved. The paper discusses the results of the tests performed at the high heat flux test facility GLADIS. The experimental results compared to transient nonlinear fine element method (FEM) calculations confirm a high thermal safety margin of the target design sufficient for plasma operation in W7-X.
\end{abstract}

PACS number: 52.55.Rk

* Corresponding author. Tel.: +49 8932991228;

fax: +49 8932991212 .

E-mail address: henri.greuner@ipp.mpg.de (H. Greuner).

\section{Introduction}

The envisaged steady-state operation of $\mathrm{W} 7-\mathrm{X}$ requires the installation of $19 \mathrm{~m} 2$ of actively water cooled divertor target

area [1]. This area will be assembled from 890 target elements. The target elements are made of $\mathrm{CuCrZr}$ heat sinks covered with flat tiles of carbon-fibre-composite (CFC) NB31 as plasma facing material. They are designed to withstand a steady-state heat flux of 10 $\mathrm{MW} / \mathrm{m}^{2}$ and a power load of up to $100 \mathrm{~kW}$ for long term plasma operation of $\mathrm{W} 7-\mathrm{X}$. The target element must allow a limited operation time at $12 \mathrm{MW} / \mathrm{m}^{2}$ steady-state and should not fail for short pulses of up to $15 \mathrm{MW} / \mathrm{m}^{2}$ for cooling conditions in the subcooled nucleate boiling regime [2]. To provide a sufficient safety margin during operation, the critical heat flux (CHF) of the target has to be $>25 \mathrm{MW} / \mathrm{m}^{2}$. A set of 20 full scale pre- series elements (length $250 \mathrm{~mm}$, width $57 \mathrm{~mm}$, covered with ten CFC NB31 flat tiles per element, $8 \mathrm{~mm}$ CFC thickness) was manufactured by PLANSEE SE to validate the materials and manufacturing technologies prior to the start of series production. The CFC tiles are bonded to the heat sink with an intermediate $\mathrm{Cu}$ compliant layer manufactured by Active Metal Casting (AMC®) [3]. These 20 elements were tested in the ion beam high heat flux test facility GLADIS in consecutive steps of power loading. At first, a screening at power densities from $6-10 \mathrm{MW} / \mathrm{m}^{2}$ and $15 \mathrm{~s}$ duration was performed. Afterwards, all elements were loaded at $10.5 \mathrm{MW} / \mathrm{m}^{2}$ for $80-100$ cycles and some up to 1000 cycles to characterize their fatigue behaviour. Six elements were additionally loaded with $13.5 \mathrm{MW} / \mathrm{m}^{2}$ and 50-100 cycles [4]. The results obtained demonstrate the reliability of the target concept for cyclic heat loads up to a factor of 1.3 of the nominal heat load. After 10.5 and $13.5 \mathrm{MW} / \mathrm{m}^{2}$ cycling three 
elements were additionally tested with heat loads beyond the expected operating conditions to evaluate the limits of thermohydraulical and -mechanical design.

\section{Experimental evaluation of the power load limits}

\subsection{Heat loading conditions in GLADIS}

The target elements were installed perpendicular to the ion beam axis in the GLADIS facility [5]. The radial beam power density distribution at the target position was measured and checked with a calorimeter during the test campaign. Two dimensional (2D) Gaussian fits to these data provide the heat load profiles of the beam at the target. The integral power load at the target was measured by water-calorimetry based on a calibrated turbine and PT 100 sensors. For the surface temperature measurements a $50 \mathrm{~Hz}$ IR camera plus one and twocolour pyrometers (temperature range up to 1700 and 2200 _C, respectively) were used. A CCD video camera allowed in situ visual inspection. The target elements had identically located thermocouples in the CFC ( $4 \mathrm{~mm}$ below the surface), in the middle of the $\mathrm{Cu}$ interlayer and the $\mathrm{CuCrZr}$ heat sink $(1.5 \mathrm{~mm}$ above the cooling channel).

The test conditions were similar to the W7-X full power operating requirements: cooling water velocity of $10 \mathrm{~ms}^{-1}$ in combination with swirl tapes (twist ratio 4 ), inlet temperature of _20_C and static pressure of 10 bar. For these conditions, the predicted heat transfer regimes of the target as functions of the loading are

1. $<9.5 \mathrm{MW} / \mathrm{m}^{2}$, forced convection in the single phase regime

2. $>11 \mathrm{MW} / \mathrm{m}^{2}$, onset of subcooled nucleate oiling, begin of subcooled boiling regime

3. $26 \mathrm{MW} / \mathrm{m}^{2}$, end of the partial subcooled boiling regime [2].

\subsection{Discussion of high heat flux test results}

The central tiles (numbers 4-5 and 7-9) of two elements which were previously cycled at 10 and 13.5 $\mathrm{MW} / \mathrm{m}^{2}$, were successively loaded with $14.5,16.5,18.0$, 20.5 and $24 \mathrm{MW} / \mathrm{m}^{2}$ with $15 \mathrm{~s}$ pulse duration to confirm the thermomechanical target design. Figure 1 demonstrates the target arrangement and the heat load profile at the target. The beam centre is located at tile 8 in this case. Table 1 summarizes selected examples of heat load tests and shows a comparison between measured and calculated target temperatures in the thermal equilibrium. The comparison between calculated and measured input power resulted in an agreement of typically $95 \pm 3 \%$ for the applied heat loads. The difference between measured and $2 \mathrm{D}$ fine element method (FEM) calculated temperatures resulted from the previous cycling of the component. This effect was systematically observed for

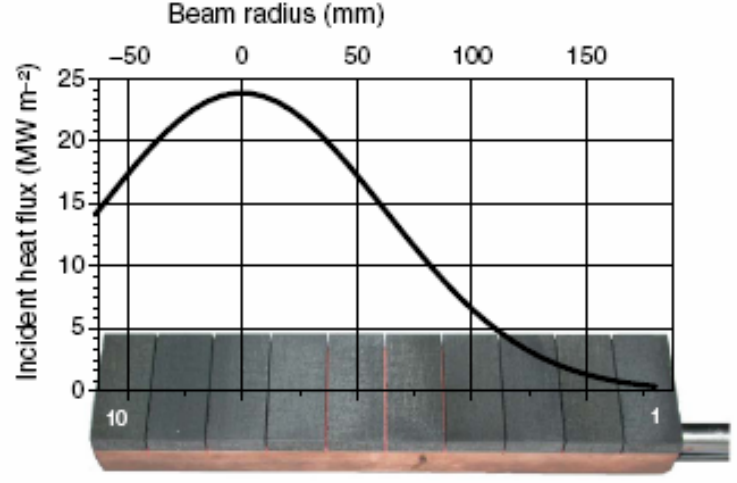

Figure 1. Schematic view of the power load distribution on the target. For this example, the beam centre is located on tile 8 . Tile numbers 1 and 10 are marked.

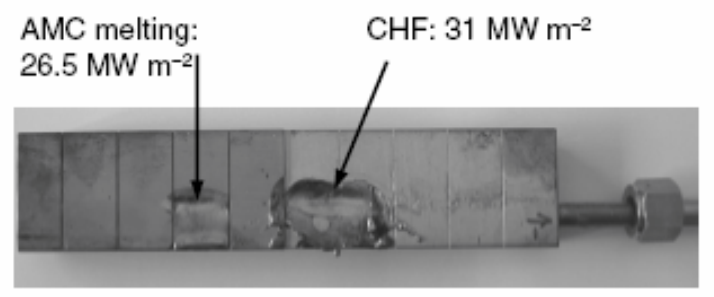

Figure 2. View of a target element surface with removed CFC tiles. 26.5 MW/ $/ \mathrm{m}^{2}$ loading resulted in the partial melting of the AMC surface. For $31 \mathrm{MW} / \mathrm{m}^{2}$ loading CHF and burn out occurred.

all elements during previous 10 and $13.5 \mathrm{MW} / \mathrm{m}^{2}$ cycling experiments [4].

For heat loads $>18 \mathrm{MW} / \mathrm{m}^{2}$ on the $8 \mathrm{~mm}$ thick CFC tiles, the surface temperature exceeded the measurement range of $2200{ }^{\circ} \mathrm{C}$. This corresponds to $\sim 1750{ }^{\circ} \mathrm{C}$ for the $6 \mathrm{~mm}$ average CFC tile thickness of the finally machined W7-X targets. Heat loads of $>22 \mathrm{MW} / \mathrm{m}^{2}$ resulted in a $\mathrm{CFC} / \mathrm{Cu}$ interlayer temperature close to the expected melting point of $1100{ }^{\circ} \mathrm{C}$. CFC tiles without previous defects withstood 6-8 loadings of $24 \mathrm{MW} / \mathrm{m}^{2}$ and $15 \mathrm{~s}$ before bonding damage started at the outer edge above the outlet cooling channel. After additional pulses the defects grow fast and result in a strong overheating and erosion of the CFC.

Based on the strong carbon evaporation and light emission from an overloaded CFC tile, it should be possible to detect excessive heat fluxes to targets during the operation of W7-X quickly. The maximum allowed temperature for the $\mathrm{CFC} / \mathrm{Cu}$ interlayer without melting will be reached after a $6 \mathrm{~s}$ loading. Before this time the overloading must be stopped in order to avoid the consequent detachment of CFC tiles.

To evaluate the predicted end of the subcooled boiling regime, an additional element with removed CFC tiles was loaded up to $26 \mathrm{MW} / \mathrm{m}^{2}$. As shown in figure 2 , this heat load resulted in a partial melting of the AMC surface, but not in a collapse of the heat transfer. 


\subsubsection{Heat loading of end tile.}

Of special interest was the investigation of the heat removal capability of the target end tile. The specified nominal heat load on this tile is reduced to $8 \mathrm{MW} / \mathrm{m}^{2}$ because it covers the U-bends of the cooling channels. The end tile withstood eight pulses of $17.5 \mathrm{MW} / \mathrm{m}^{2}, 15$ $\mathrm{s}$, without any visible defects.

\subsubsection{CHF test.}

The melting of the target cooling structure due to thermal overload and subsequent break down of the heat transfer to the cooling water is considered to be catastrophic damage. The target design and cooling conditions have to avoid such an event during operation in $\mathrm{W} 7-\mathrm{X}$. The calculated $31 \mathrm{MW} / \mathrm{m}^{2} \mathrm{CHF}$ of the target ensures the requested safety factor of 2.5 to the nominal heat flux in W7-X. The CHF prediction was calculated using the TONG-75CEA correlation, corrected for swirl tubes and one-side heating conditions [6]. The cooling conditions in the outlet channel $\left(80^{\circ} \mathrm{C}\right.$ water temperature, $10 \mathrm{~ms}^{-1}$ axial velocity, 10 bar) determine the minimum $\mathrm{CHF}$ of the target. A calculated local $\mathrm{CHF}$ of $40 \mathrm{MW} / \mathrm{m}^{2}$ at the wall corresponds to a target surface $\mathrm{CHF}$ of $31 \mathrm{MW} / \mathrm{m}^{2}$ due to the geometric heat flux concentration between the loaded surface and the cooling channel. For the same loading, a reduction of cooling water velocity to $8 \mathrm{~ms}^{-1}$ resulted in a decrease of the target $\mathrm{CHF}$ to $25 \mathrm{MW} / \mathrm{m}^{2}$ due to the reduced heat exchange and the increase of local water temperature. The CHF test was performed with a stepwise increase of power load up to $31 \mathrm{MW} / \mathrm{m}^{2}$ on a target with removed $\mathrm{CFC}$ and $\mathrm{AMC}\left(15^{\circ} \mathrm{C}\right.$ cooling water inlet, $10.4 \mathrm{~ms}^{-1}$ axial velocity, 10 bar static). Figure 2 shows the molten cooling structure after the CHF test. Burnout occurred after $2.6 \mathrm{~s}$ heating for an estimated water temperature of $80-90{ }^{\circ} \mathrm{C}$. This result exactly meets the local and temporal predictions. It confirms the validity of the used CHF correlations for the W7-X target design.

\section{Finite element modelling and simulation}

A fully 3D nonlinear thermo-mechanical FE simulation of the component during $15 \mathrm{~s}$ heating with $10.5,13.5$ and $18 \mathrm{MW} / \mathrm{m}^{2}$ and cooling down was performed to analyse the evolution of temperatures, stresses and strains. Making use of symmetry conditions, a quarter of the full target element was modelled in ABAQUS [7]. Initial stresses resulting from the heat treatment of the manufacturing process are accounted for. In particular, the FE model includes the thermal and mechanical loading and cooling boundary conditions as given at the GLADIS facility. A detailed evaluation of the stressing was performed for the target element focused on the $\mathrm{CFC} / \mathrm{Cu}$-interface as the most critical region. Individual material definitions are adopted for the metallic and the CFC sections. Temperaturedependent thermo-elasto-plastic isotropic material descriptions are used for (AMCR

) and $\mathrm{CuCrZr}$, respectively. For the CFC NB31, thermo-elastic orthotropic properties are adopted including nonlinear elasticity and progressive damage.

\subsection{Discussion of FEM simulation results}

The temporal and spatial evolution of temperatures, stresses and strains are calculated for the three HHF load profiles as given above and are evaluated for the CFC sections in terms of maximum principal stresses, damage variables as well as total, elastic and thermal principal strains and for the metallic sections in terms of von Mises equivalent stresses, equivalent plastic strains as well as total, elastic and thermal principal strains. For the investigated single exposure HHF load levels, it is shown that plastic straining of the $\mathrm{Cu}$ interlayer is considerably increased when increased HHF loading is applied. This is due to increased temperatures acting on the interlayer which resulted in decreasing yield strength of the AMC. The plastic strains increased from 0.0012 to 0.0017 and 0.0038 during heating with $10.5,13.5$ and $18 \mathrm{MW} / \mathrm{m}^{2}$ respectively. After cooling down, the corresponding plastic strains are: $0.0012,0.0026$ and 0.0054 . In particular for higher HHF loads, the enlarged plastic zone progresses from the free edge towards the centre of the component whereas for the nominal HHF load the plastic zone is mainly restricted to a small area of the free edge region.

Table 1. Comparison of the measured and calculated heat loads and the corresponding temperatures of the target.

\begin{tabular}{ccccc}
\hline $\begin{array}{c}\text { Central heat flux } \\
\left(\mathrm{MW} \mathrm{m}{ }^{-2}\right)\end{array}$ & $\begin{array}{c}\text { Power load at target } \\
\text { calc./measured }(\mathrm{kW})\end{array}$ & $\begin{array}{c}\text { Temp. CuCrZr } \\
\text { calc./measured }\left({ }^{\circ} \mathrm{C}\right)\end{array}$ & $\begin{array}{c}\text { Temp. (AMC }) \\
\text { calc./measured }\left({ }^{\circ} \mathrm{C}\right)\end{array}$ & $\begin{array}{c}\text { Temp. CFC surface } \\
\text { calc./measured }\left({ }^{\circ} \mathrm{C}\right)\end{array}$ \\
\hline 10.4 & $86 / 82 \pm 2$ & $250 / 335$ & $400 / 480$ & $1100 / 1143$ \\
13.5 & $102 / 98 \pm 2$ & $300 / 423$ & $505 / 614$ & $1500 / 1653$ \\
18.0 & $144 / 137 \pm 3$ & $365 / 596$ & $655 / 760$ & $2130 /<2200$ \\
20.5 & $155 / 144 \pm 3$ & $400 / 658$ & $530 / 874$ & $2450 /$ upper range \\
24.0 & $177 / 155 \pm 3^{2}$ & $460 /-$ & $840 /-$ & $2800 /$ upper range \\
26.5 & $193 / 191 \pm 3^{b}$ & $490 /-$ & $885 /-$ & Removed \\
31.0 & $244 /$ bum out & $-/-$ & Removed & Removed \\
\hline
\end{tabular}

${ }^{a}$ Includes $8 \mathrm{~kW}$ thermal radiation power.

${ }^{b}$ Element with removed CFC tiles. 
End of heating

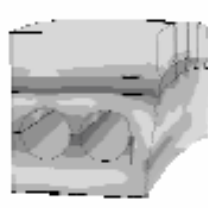

(a)

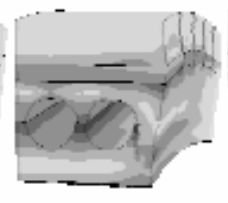

(b)

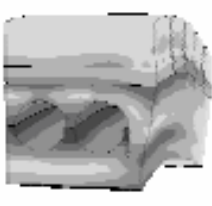

(c)

c)

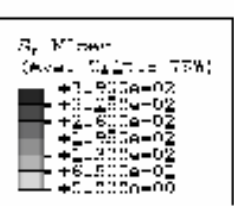

End of cooling down

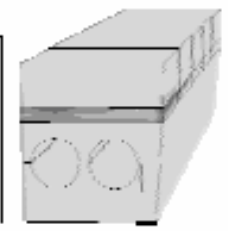

(d)

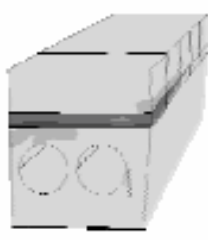

(e)

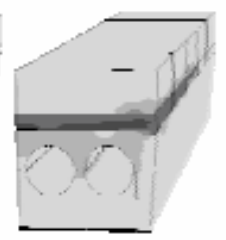

(f)

Figure 3. Calculated distributions of the von Mises stresses (MPa) at the end of the high heat flux loading for the individual HHF load levels $10.5,13.5$ and $18 \mathrm{MW} / \mathrm{m}^{2}$ (a), (b) and (c) correspondingly, at the end of the subsequent cooling down to 20 _C for the cases (d), (e) and (f).

Furthermore, for higher HHF loads additional plastic strain is predicted during the subsequent cooling down which is not found for the nominal HHF load. Although higher thermally induced straining is also predicted for the interlayer, the stress levels in the interlayer decrease when increased HHF loads are applied. Consequently, the maximum stress levels at the AMC/CFC interface decrease during application of higher HHF loads. Figure 3 (a)-(c) show decreasing von Mises stresses in the $\mathrm{Cu}$ interlayer as well as in the CFC section particularly at the free edge. However, after cooling down the higher HHF loads accumulate more additional plastic strain than the nominal HHF load does and, consequently, the residual stress state is more pronounced for the higher HHF loads than for the nominal one (figure 3 (d)-(f)).

\section{Conclusions}

Three W7-X pre-series target elements were loaded up to $24 \mathrm{MW} / \mathrm{m}^{2}$ (factor of 2.4 of the nominal loading) with pulses of $15 \mathrm{~s}$ duration in a stable heat transfer regime. $24 \mathrm{MW} / \mathrm{m}^{2}$ heat load resulted in a CFC surface temperature beyond $2200{ }^{\circ} \mathrm{C}$ and a corresponding CFC bonding temperature close to the melting point of $\mathrm{Cu}$ after $6 \mathrm{~s}$ loading. The subsequent partial detachment of the tile was observed, but no tile loss occurred.

For $18 \mathrm{MW} / \mathrm{m}^{2}$ heat loads, no bonding defects were seen. This experimental result confirms the corresponding FEM analysis. Compared to the nominal $10 \mathrm{MW} / \mathrm{m}^{2}$ loading, the higher component temperature results in reduced stress during loading, but also in increased plastic deformation of the $\mathrm{Cu}$ interlayer close to the CFC interface. This effect allows single pulses of overloading to be tolerated.
The experimental measured CHF of the target of 31 $\mathrm{MW} / \mathrm{m}^{2}$ exactly meets the prediction and demonstrates the high thermal safety margin of the cooling structure. All these tests confirm the reliability of the correlations of heat transfer and CHF and the resulting thermalhydraulic design. The high thermal performance of the manufactured pre-series elements demonstrated the ability to withstand the W7-X operating conditions with a reliable safety margin.

\section{References}

[1] Renner H, Boscary J, Erckmann V, Greuner H, Grote H, Sapper J, Speth E, Wesner F and Wanner M 2000 Nucl. Fusion 401083

[2] Greuner H, Herrmann A, Renner H, Chappuis P and Mitteau R 1998 Fusion Technol. 1249

[3] Boscary J, Greuner H, Mendelevitch B, Schedler B, Scheiber K, Schlosser J and Streibl B 2005 Fusion Eng. Des. 75-79 451

[4] Greuner H, Boeswirth B, Boscary J, Plankensteiner A and Schedler B 2006 High heat flux tests of the WENDELSTEIN 7-X pre-series target elements, experimental evaluation of the thermo-mechanical behaviour Fusion Eng. Des. 82 (2007)

1713-1719 [5] Greuner H, Boeswirth B, Boscary J and McNeely P 2004 High heat flux facility GLADIS operational characteristics and results of W7-X pre-series target tests J. Nucl. Mater. 367-370 (2007) 1444-1448 [6] Smid I, Schlosser J, Boscary J, Escourbiac F and Vieder G 1996 Fusion Technol. 1263

[7] Plankensteiner A, Leuprecht A, Schedler B, Scheiber K-H and Greuner H 2006 Finite element based design optimization of Wendelstein 7-X divertor components under high heat flux loading Fusion Eng. Des. 82 (2007) 1813-1819 